\title{
A new dawn in prostate cancer management: Do we have the trials to support it?
}

\author{
D. Andrew Loblaw, MD, MSc, FRCPC, CIP
}

Department of Radiation Oncology, Odette Cancer Centre, Sunnybrook Health Sciences Centre, University of Toronto, Toronto, ON

See related article on page 173.

Cite as: Can Urol Assoc J 2011;5(3):180-1; D01:10.5489/cuaj.11098

$\mathrm{P}$ ai and colleagues report a small randomized controlled trial (RCT) examining whether men who receive 6 months of neoadjuvant androgen deprivation therapy for cytoreduction recover faster whether they receive a monthly luteinizing hormone-releasing hormone agonist (LHRHa) or an injection every 3 months. ${ }^{1}$ Unfortunately, due to accrual and eligibility issues, the authors were not able to complete the study in a timely manner and only 46 of the planned 100 patients were available for data analysis. There was a difference in testosterone recovery (4 vs. 8 months), but this failed to reach statistical significance $(p=0.27)$ and was much smaller than was seen in the authors' previous retrospective study (8 vs. 16 months).

The fact that the authors failed to achieve the target sample size is the greatest symptom of the challenges we face with clinical trials. Clinical trials are scientifically and ethically the only way for medicine to evolve to meet the many challenges in our health care systems. Duley and colleagues identified a number of barriers to conducting phase 3 studies: inadequate funding, overly complex regulations producing needlessly complex trial procedures, excessive monitoring, over restrictive interpretation of privacy laws without evidence of subject benefit and inadequate understanding of methodology. ${ }^{2}$

Even if these barriers can be overcome, Dilts estimates that only 1 in 3 trials reach their accrue goals (D Dilts, personal communication 2009). Lara and colleagues would add patient and physician lack of equipoise to the above list. ${ }^{3}$ Given our climate of health care consumerism, the lack of equipoise is a particular challenge when evaluating interventions that are available off study - why, as a patient, would you subject yourself to a random allocation of treatment $A$ versus B when you can choose? This effect was seen in 3 high-profile Canadian-led prostate cancer RCTs that failed or are struggling to reach their accrual goals: (1) NCIC CTG's PR 10 study (SPIRIT: prostactectomy vs. brachytherapy), (2) OCOG PR1 (ELAAT: early vs.. deferred androgen ablation therapy) and (3) NCIC CTGs PR11 (START: active surveillance vs. radical treatment). We need to question whether we can complete a pragmatic RCT in prostate cancer. Are there other methodologies, like the patient preference trial, that may be appropriate to inform evidence-based policy decisions?

Getting back to the above study, we might ask why this study was done. Permanent seed brachytherapy is a single, outpatient procedure with a 1-hour recovery time and available mature outcomes. Twelve-year biochemical diseasefree survival (bDFS) rates are $98 \%$ and $96 \%$ for low- and intermediate-risk disease. ${ }^{4,5}$ Sexual and overall quality of life (QOL) scores are better than prostatectomy with no worse bowel QOL. ${ }^{6}$ Investigators have reported that brachytherapy has better long-term control than external beam radiotherapy (EBRT) at median doses of 68 Gy (95 vs. $75 \%$ at 7 years bDFS $)^{7}$ or even at 81 Gy using intensity-modulated radiation therapy (IMRT) (95 vs. $89 \%$ at 7 years bDFS). ${ }^{8}$ Quality is important - the higher the dose to $90 \%$ of the prostate, the greater the likelihood of controlling the prostate-specific antigen. ${ }^{9}$ The problem with brachytherapy is that a good quality implant cannot be achieved in every man, particularly those with large (>60 cc) prostates.

This is where cytoreduction comes in; 5-alpha reductase inhibitors (5-ARIs), antiandrogens + 5-ARIs or LHRHa can provide 17,31 and $40 \%$ volume reductions with variable degrees of libido loss, fatigue and hot flashes. ${ }^{10}$ However, most men are not keen to expose themselves to these side effects and the costs of these medications are significant, even short term.

A new question emerges: Can we safely biologically dose escalate radiotherapy doses in men with prostates larger than 
$60 \mathrm{cc}$ ? Stereotactic EBRT techniques have been developed which require only 5 treatments, deliver biologically similar doses to brachytherapy, are well-tolerated, highly effective and can treat prostates up to 90 cc. ${ }^{11.12}$

Further follow-up is needed for these emerging technologies, but I believe we are in a renaissance in prostate cancer management. I predict that within the decade we will be able to demonstrate in clinical trials that 5 or less outpatient treatments will have a $99 \%$ success rate and less than $1 \%$ severe side effects. We just need to put our collective minds to the challenge and as androgen deprivation therapy is such an effective adjuvant, it should be considered as part of the potential solution.

Competing interests: None declared.

This paper has been peer-reviewed.

\section{References}

1. Pai HH, Pickles $T$, Keyes $M$, et al. Randomized study evaluating testosterone recovery using short versus long-acting luteinizing hormone releasing hormone agonists. Can Urol Assoc J 2011;5:173-9; D01:10.5489/cuaj.10102

2. Duley L, Antman K, Arena J, et al. Specific barriers to the conduct of randomized trials. Clin Trials 2008;5:40-8.
3. Lara PN Jr, Higdon R, Lim N, et al. Prospective evaluation of cancer clinical trial accrual patterns: identifying potential barriers to enrollment. J Clin Oncol 2001;19:1728-33.

4. Butler WM, Stewart RR, Merrick GS. Evaluation of radiobiologic biochemical control in a large permanent prostate brachytherapy population from a single institution using AAPM TG-137 parameters. Brachytherapy 2011;10:16-28.

5. Taira AV, Merrick GS, Butler WM, et al. Long-term outcome for clinically localized prostate cancer treated with permanent intersititial brachytherapy. Int J Radiat Oncol Biol Phys 2011;79:1336-42.

6. Crook JM, Gomez-Ituriaga A, Wallace $K$, et al. Comparison of health-related quality of life 5 years after SPIRIT: Surgical Prostatectomy versus Interstitial Radiation Intervention Trial. J Clin Oncol 2010;29:362-8.

7. Pickles T, Keyes M, Morris WJ. Brachytherapy or conformal external radiotherapy for prostate cancer: a single-institution matched-pair analysis. Int I Radiat Oncol Biol Phys 2010;76:43-9.

8. Zelefsky MJ, Yamada Y, Pei X, et al. Comparison of tumor control and toxicity outcomes of high-dose intensity-modulated radiotherapy and brachytherapy for patients with favorable risk prostate cancer. Urology 2011;77:986-90.

9. Potters L, Roach lii M, Davis BJ, et al. Postoperative nomogram predicting the 9-year probability of prostate cancer recurrence after permanent prostate brachytherapy using radiation dose as a prognostic variable. Int J Radiat Oncol Biol Phys 2010;76:1061-5.

10. Quon H, Loblaw DA. Androgen deprivation therapy for prostate cancer-review of indications in 2010. Curr Oncol 2010;17(Suppl 2):S38-44.

11. Boike TP, Lotan Y, Cho LC, et al. Phase I dose-escalation study of stereotactic body radiation therapy for low- and intermediate-risk prostate cancer. J Clin Oncol 2011;29:2020-6. Epub 2011 Apr 4.

12. Quon $\mathrm{H}$, Cheung $\mathrm{P}$, Cesta A, et al. Phase 2 study of a five-fraction hypofractionated accelerated radiotherapy treatment for low risk localized prostate cancer: Toxicity results of pHART3. 2010 GU Cancers Symposium Proceedings 2010:abstract 48.

Correspondence: Dr. Andrew Loblaw, Department of Radiation Oncology, Odette Cancer Centre, Sunnybrook Health Sciences Centre, University of Toronto, 2075 Bayview Ave., Toronto, ON M4N 3M5; fax: 416-480-6002; andrew.loblaw@sunnybrook.ca 